\title{
WHO'S WHO
}

\section{Jun-le Zhao, Guo-yue Yang \\ Guang-ming Zhai: a Brief Biography}

\author{
Guang-ming Zhai \\ Petroleum Geologist
}

Professor-engineer and vice chairman of the Expert Committer of the Advisory Center of China National Petroleum Corporation

Professor Guang-ming Zhai was born in Yichang City of Hubei Province in October 1926. He graduated from the Department of Geology of Peking University in 1950 and became one of the members of the Chinese Academy of Engineering (CAE) in 1995.

Professor Zhai served successively as the chief geologist of Yumen Oil Production Factory, the chief geologist and director of the Geological Exploration Department

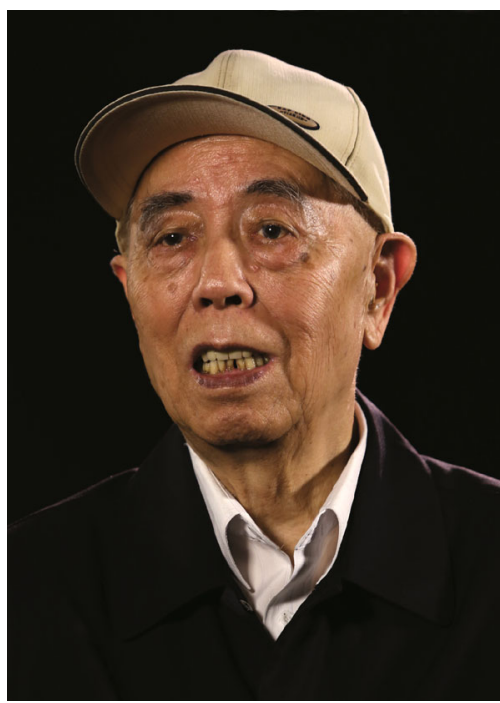
of the Ministry of Petroleum Industry, the president of the Institute of Petroleum Exploration Sciences of China National Petroleum Corporation (CNPC), and the chairman of the Exploration Section of the Advisory Center of CNPC. Now, he is the vice chairman of the Expert Committee of the Advisory Center of CNPC.

Professor Zhai, since the 1950s, has engaged in the work of oil exploration, and contributed much to the construction of such large oilfields as the Shengli Oilfield, the Daqing Oilfeild, and the Liaohe Oilfeild. He is one of the pioneers in the research and exploration of rich oil resources in the basin areas in West China, including the Ordos Basin, the largest of its kind in China.

Professor Zhai developed theories of oil deposition zones and oil accumulation laws, which played a significant role in petroleum exploration in China. He chaired and completed the research project "Study on the Geological Laws of the Compound Oil and Gas Zone in the Gulf of Bohai and Their Application", and produced the theory of multiple oil and gas accumulation zone, which was awarded the grand prize of the National Scientific and Technological Progress Prizes in 1985. He presided over the research projects on petroleum and natural gas distribution in China, and proposed the comprehensive analytical theory of the histories of petroleum and gas formation, which opened some new areas and new fields. He proposed the general exploration plans of scientific exploring wells, which brought a great success to the petroleum industry in China. After that, he won the second prize of the National Scientific and Technological Progress Prizes, the first prize for the Scientific and Technological Progress Prizes of CNPC. And what's more, in 1991, he won the "Labor Day Medal of China", the "Scientific and Technological Experts with Outstanding Contributions to Oil Industry"

Manuscript received January 1, 2015; accepted September 5, 2015

Jun-le Zhao $(\bowtie)$

Academy of Education Studies (School of Public Administration), Central South University, Changsha 410083, China

Email: wenqian0320@163.com 
Medal, and a special government allowance from the State Council of China. He won the first prize of the CNPC Great Achievement Prizes in 1995.

After 1992, Professor Zhai led teams for the second evaluation of oil and gas resources of the oil system, which provided a scientific basis for the long-term planning and development of China's future oil industry. And after 1998, he chaired the strategic research of petroleum exploration in China, and led teams for the research projects of "Plate Tectonic Evolution and Oil-Gas Basin Formation", and pointed out that there are many sedimentary basins with rich reserves of oil and gas resources in Central and West China, and put forward proposals of concrete targets of exploration. He thought it was necessary to explore new areas and new strata in the basins of East China, located the areas with potential reserves, and described the features of order distribution of the oil and gas in the basins of China. In 2014, he was invited by the Ministry of Land and Resources to work as the chairman scientist for the third assessment project of oil and gas resources in China.

Professor Zhai pointed out that in the different stages of exploration, there could be reserves difficult to find, and reserves difficult to develop with the limitation of technology and exploring devices. With the development of science and technology, those oil resources deeply buried underground will be found, which conform to the oil geological storage conditions of China. He reconstructed his experiences, and produced "Seven Steps of Innovation": step one, open strategic thinking; step two, solid engineering design; step three, specific implementation plan for every idea; step four, strong mind, belief and measures to continue; step five, summary in every stage; step six, adjustment of the original plan according to the new situation; step seven, completion with the expected effect.

Professor Zhai authored many books and papers, the major ones of which include: The Assessment of Oil and Gas Resources in South Sea of China; The Oil and Gas Resources in the Northwest of China and the Exploring Visions; The Classification of Sedimentary Basins and the Distribution of Oil and Gas in China; The Structure and Oil Gas Distribution in Ordos Basin; The Oil and Gas Distribution in the Bohai Bay Basin; and, Petroleum Geology of China, which won him the first prize of the National Excellent Science and Technology Books Prizes.

As an outstanding technologist and scientist, Professor Zhai pays attention not only to his research and exploration but also to fostering of young scientists, especially the innovative ones. He is an influential educator. 